\title{
UMA ANÁLISE PRELIMINAR DA ASSOCIÇÃO ENTRE EVENTOS DE RETORNO DE UMIDADE COM JATO DE BAIXOS NÍVEIS NO PERIOD FRIO DE 2004 A 2011
}

\author{
Felipe Daniel Cristo Espindola, Ernani de Lima Nascimento \\ Universidade Federal de Santa Maria, Santa Maria, RS \\ Departamento de Física, Programa de Pós-graduação em Meteorologia
}

\section{RESUMO}

Esse trabalho fará uma analise preliminar entre a possível associação de Jatos de Baixos Níveis com eventos de Retorno de umidade.

\begin{abstract}
This research will make an analysis preliminary between possible associations of low-level jet with events of moisture return.
\end{abstract}

\section{INTRODUÇÃO}

A região da Bacia do Prata é frequentemente influenciada pelos sistemas sinóticos migratórios de, e, portanto apresenta episódios de alternância entre intrusões de ar quente e úmido proveniente do trópicos e de ar frio e seco da Patagônia (BERBERY e COLLINI, 2000; SELUCHI e MARENGO, 2000). Não raro, após a passagem de uma massa de ar frio e seco com ventos predominantemente de sul, observar a gradual reversão da direção do vento para o setor norte acompanhada do aumento da umidade e da temperatura à medida que o anticiclone desloca-se corrente abaixo adquirindo características tropicais. Essa mudança nas características da massa de ar durante o deslocamento do anticiclone recebe o nome de "Retorno de Umidade(RU)" (CRISP e LEWIS, 1992; WEISS, 1992). No entanto, o processo de RU associado à sistemas de tempo na Bacia do Prata requer um estudo mais específico, como já realizado para América do Norte (CRISP e LEWIS, 1992; THOMPSON et al 1994)

Esse trabalho tem por objetivo fazer uma análise preliminar da possível associação entre eventos de jato de baixos níveis (JBN) com o fenômeno de RU ocorrido sobre a BP no período frio do ano, ou seja, entre maio e setembro. A pesquisa foi realizada com base em de 22 episódios de RU ocorridos, no período frio, entre 2004 e 2011.

\section{DADOS E MÉTODOS}

Para este trabalho foram utilizadas análises diárias (00Z, 06Z, 12Z e 18Z) do modelo Global Forecast System (GFS) do National Centers for Environmental Prediction (NCEP) sobre a América do Sul com $1^{\circ}$ de espaçamento de grade para o período entre 2004 e 2011, sempre entre maio e setembro. Para os 22 casos de RU identificados foi realizado uma análise sinótica das variáveis pressão reduzida ao nível do mar, Vento a 10m, temperatura a 
$2 \mathrm{~m}$, vento e umidade especifica em $850 \mathrm{hPa}$, altura geopotêncial em $500 \mathrm{hPa}$, vento em 200 $\mathrm{hPa}$, energia potencial disponível e água precipitável.

\section{RESULTADOS}

Através da análise sinótica dos 22 casos de RU ocorridos na BP no período frio entre 2004 e 2011, é possível identificar que simultaneamente à segunda fase do RU (CRISP e LEWIS, 1992) acontece a formação de um sistema de baixa pressão no noroeste da Argentina. A configuração sinótica com o sistema anticiclonico posicionado no atlântico sul e o sistema ciclonico no noroeste da Argentina provoca uma aceleração do escoamento em baixos níveis, o que facilita a convergência de ar quente e umidado para a região do Prata. Observase que essa configuração sinótica possui suporte em níveis médios com à aproximação de um cavado pelos Andes e com a crista estabelecida na região do Prata. A configuração descrita que pode ser visualizada na Figura 1 através dos campos médios dos 22 casos - pode originar a formação de um jato de baixos níveis direcionado para a região do Prata (NICOLINI et al 2012).

\section{CONSIDERAÇÕES FINAIS}

O fenômenos de retorno de umidade e de jatos de baixos níveis tem um importante papel no transporte de umidade para a Bacia do Prata, no entanto ainda não existem estudos que relacionam episódios de Retorno de Umidade com eventos de jatos de baixos níveis.

A analise sinótica realizada para esse trabalho mostra que alguns eventos de retorno de umidade podem originar episódios de jato de baixos níveis. Essa pesquisa prosseguirá para tentar contribuir com o entendimento da relação entre eventos de Retorno de Umidade com ocorrências de jato de baixos níveis.

\section{REFERÊNCIAS BIBLIOGRAFICAS}

BERBERY, E. H.; COLLINI, E. A. Springtime precipitation and water vapor flux over southeastern South America. Mon. Wea. Rev., v. 128, p.1328-1346, 2000.

CRISP, C. A.; LEWIS, J. M. Return flow in the Gulf of Mexico. Part I: A classificatory approach with a global historical perspective. J. Appl. Meteor., v. 31, p. 868-881, 1992.

NICOLINI et., al, Enhanced precipitation over south estern south America related to strong low-level jet events during austral warm season.

THOMPSON, L. R.; LEWIS, M. J.; MADDOX, A. R. Autumnal return of tropical air to the gulf of mexico's coastal plain. Weather and forecasting., v. 9, p. 348-360, 1994.

WEISS, S. J. Some aspects of forecasting severe thunderstorms during cool-season returnflow episodes. J. Appl. Meteor., v. 31, p. 964-982, 2000. 
$\mathrm{V} 10 \mathrm{~m}(\mathrm{~m} / \mathrm{s}), \mathrm{t} 2 \mathrm{~m}(\mathrm{C})$ e $\mathrm{PNM}(\mathrm{hPa})$
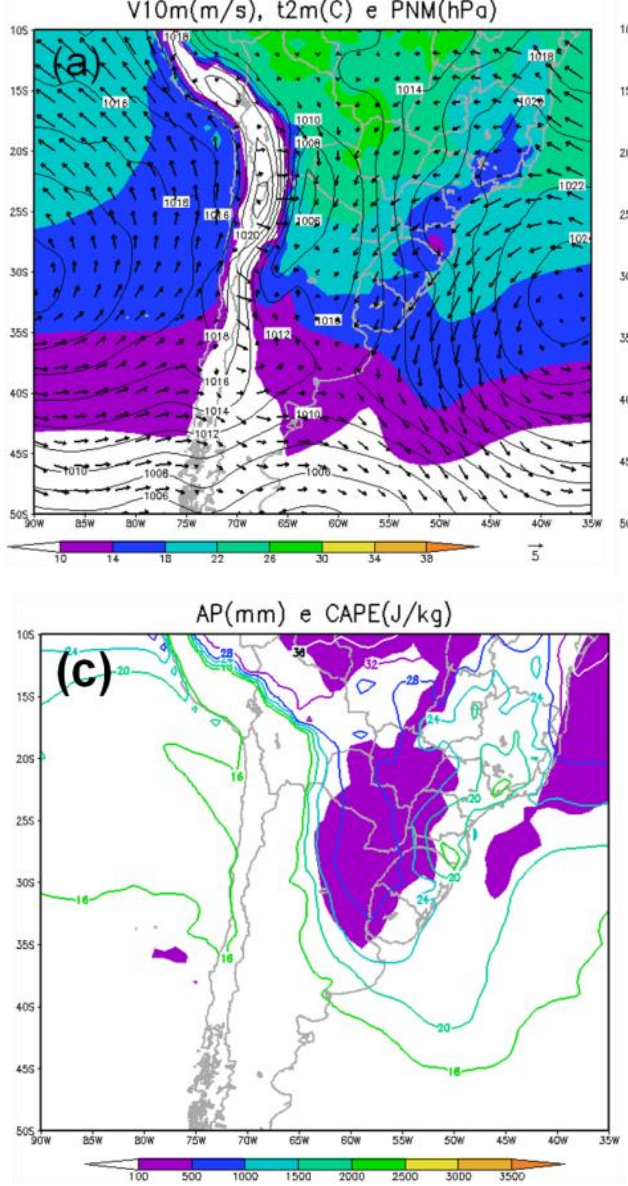

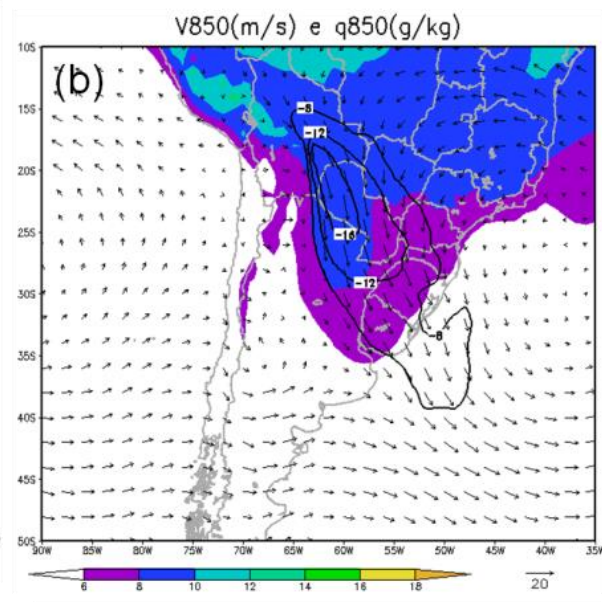

$\operatorname{HGT500}(\mathrm{gpm}), \mathrm{V} 200(\mathrm{~m} / \mathrm{s})$ e $\operatorname{MagV} 200(\mathrm{~m} / \mathrm{s})$

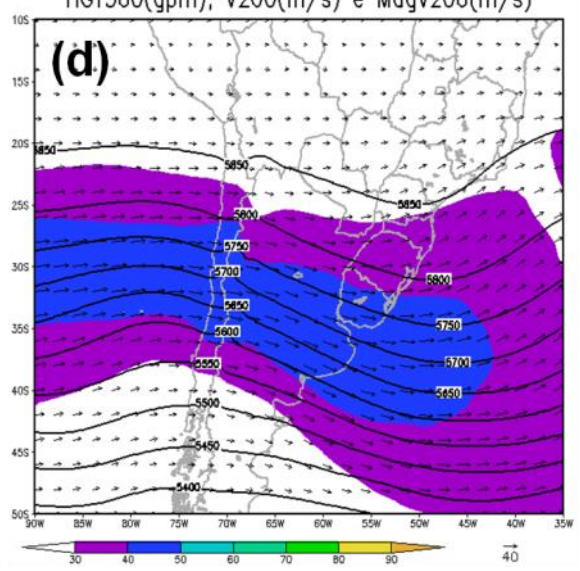

Figura 1 - Mapas sinóticos médios para os 22 casos de Retorno de umidade ocorrido sobre a Bacia do Prata no período frio entre 2004 e 2011. (a) vento a 20 metros, temperatura a 2 metros e pressão ao nível do mar; (b) Vento e umidade específica em $850 \mathrm{hPa}$; (c) Agua precipitável e energia potencial disponível; (d) Altura geopotencial em $500 \mathrm{hPa}$, vento e magnitude do vento em $300 \mathrm{hPa}$. 